\title{
Development for the Integrated Management System for the Safe Transport of Dangerous Goods Vehicles
}

\author{
Jong-Un Won ${ }^{1}$, Jae-Won Kim ${ }^{2}$ and Yong-Jang Kwon ${ }^{3}$ \\ ${ }^{1,3}$ Logistics System Research Team, Korea Railroad Research Institute \\ 176, Railroad museum road, Uiwang-si, Gyeonggi-do, 437-757, Korea \\ ${ }^{2}$ Natural Science Research Institute, Korea University \\ 145, Anam-ro, Seongbuk-gu, Seoul, 136-704, Korea) \\ 1juwon@krri.re.kr, ${ }^{2}$ kimjw16@korea.ac.kr, ${ }^{3} y j k w o n @ k r r i . r e . k r$
}

\begin{abstract}
In this paper, we propose the integrated management system for the safe transport of dangerous goods vehicles. It provides a safe path to reduce secondary accident damage and manages in real time the running state of the vehicle(over speeding, rapid speed-up or down, whether the vehicle is moving the given path) to prevent accident and automatically detect the vehicle accident and transfer the information concerning the accident to relevant governments to support the quick and accurate accident response. The system consists of the control center and a device attached on vehicle. They are connected with LTE(Long Term Evolution) network in real time. Therefore, we could gather all information about the status of the vehicle and the goods and then manage in real time the running vehicle no matter what a driver does. So, the transport of dangerous goods vehicles is more safety.
\end{abstract}

Keywords: hazardous material, dangerous goods, transportation, Location based Service

\section{Introduction}

As the demand for transporting dangerous goods increase, the rate of accidents also increases. [1-6]. The damages of the accidents would be extensive mainly due to secondary impact. The fire and explosion as shown in figure 1 caused by cigarettes in dealing in fuel archived illegal under the highway. The owner of the vehicle claimed a total of 12 million dollars and the recovery process took four months and social cost of 210 million dollars occurred. The cause of accident is to treat the gasoline in illegal places. If they can know correctly where the vehicle is, how long it stopped in an area where it is not permitted, it could have been prevented.

\footnotetext{
${ }^{1}$ Jong-Un Won : Logistics system research team, Korea Railroad Research Institute

${ }^{2}$ Jae-Won Kim : Natural Science Research Institute, Korea University

${ }^{3}$ Yong-Jang Kwon : Logistics system research team, Korea Railroad Research Institute
} 


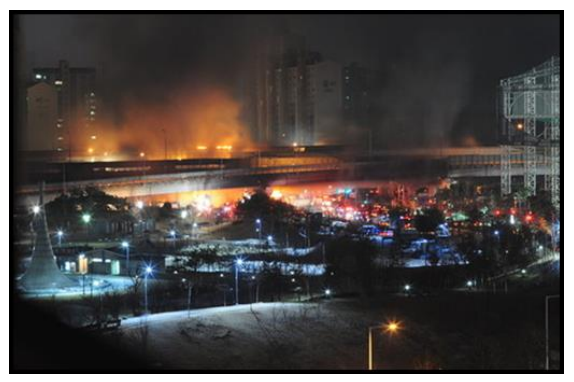

Figure 1. A Fire in the Outer Circular Highway in Seoul, Korea(2010.12.13)

In Singapore, the hazmat transport vehicle tracking system, HTVTS was introduced to tighten security regarding hazmat transportation and enhance security on the road. The system is also able to remotely immobilize a hazmat transport vehicle in the event of an emergency. The key objective of HTVTS is to reduce hazmat transportation vulnerabilities, and to prepare a system that will protect against, deter and respond to intentional or unintentional violations involving hazmat transport vehicles.

They operate HTVTS that manages the path and status of vehicle. The driver must obtain a permit for the path before driving. The vehicle must go along the approved route.[7-10] In Korea, since 2015, the path of all chemicals vehicles must be pre-approved. Good route system provides transport routs, monitoring and police enforcement. Decision support system is a key element of the system in providing safe routes. Several European countries have done pre-test in densely populated areas, tunnels, and bridges. Increased of the governmental need for management of the transport hazmat.[2]

An integrated management system for the safety transport of HAZMAT to prevent and respond to HAZMAT accidents is necessary. To provide safe path and monitoring a vehicle health in real time are key features of the system. Therefore, we develop the integrated management system for hazmat transport vehicles with path management, vehicle health management and accident response system.

We introduce the need of the integrated management system for safe transport of dangerous goods vehicle and present related systems in chapter 1, and in chapter 2 , we describe integrated management system for hazmat transportation including system architecture, path management, vehicle management, and accident management. The developed system is tested in real environment and the result is in chapter 3 and conclusion is in chapter 4.

\section{Integrated Management System for Hazmat Safety Transportation}

\subsection{System Architecture}

Integrated management system consists of the control center providing optimal path, checking the route, real-time monitoring of vehicle, accident notification and request the relevant authorities and driver device optimal path driving, the provision of the accident's recognition and corresponding manual, etc. and LTE network support nation-wide communication in real time as shown in Figure 2. 


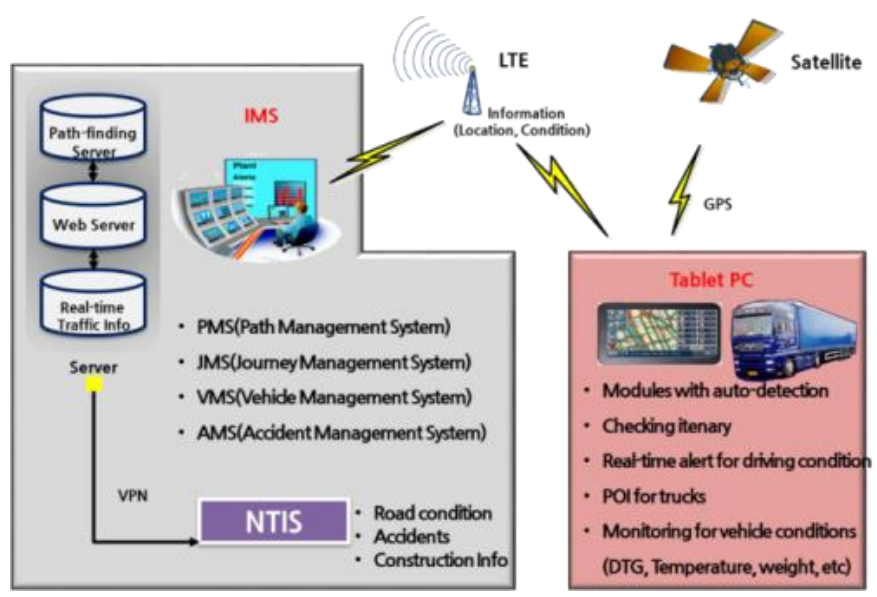

Figure 2. System Architecture

In Figure 3, before driving, an operator should schedule the path that a vehicle should run through. The scheduled path is given to the vehicle, the driver operates the vehicle through the scheduled path. During driving, all of the vehicle and driver's status information is stored in the $\log$ DB. The system is monitoring each vehicle to prevent accident, violation accessing restricted areas and path departure. If a vehicle gets any events (accident, accessing restricted areas or path departure etc.), the system alarm occurs on time. After driving, location and path log information is sent to server system(statistics DB). The system analyzes path dependence, over speeding, rapid deceleration/acceleration, illegal stop etc.

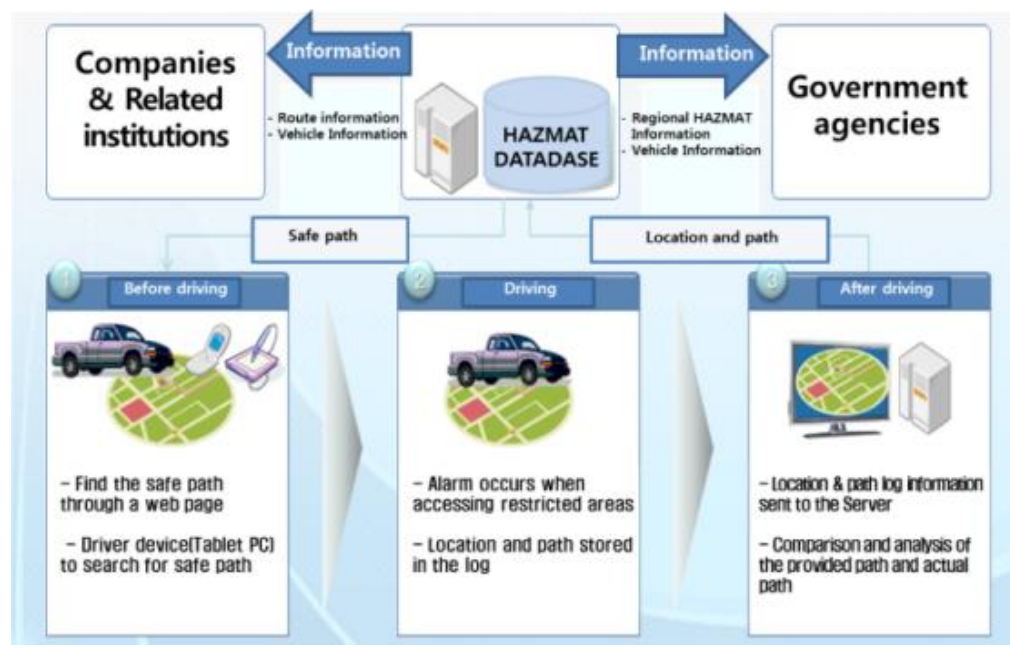

Figure 3. System Operating

\subsection{Searching for Safe Route through Path Management}

Most of the vehicles are used for car navigation that recommends time or distance minimized paths as shown in figure 4 . However, the vehicle transporting dangerous goods should run though a safe path except water protection or high density population area to prevent secondary damage that give harm to unspecified people [11-15]. 


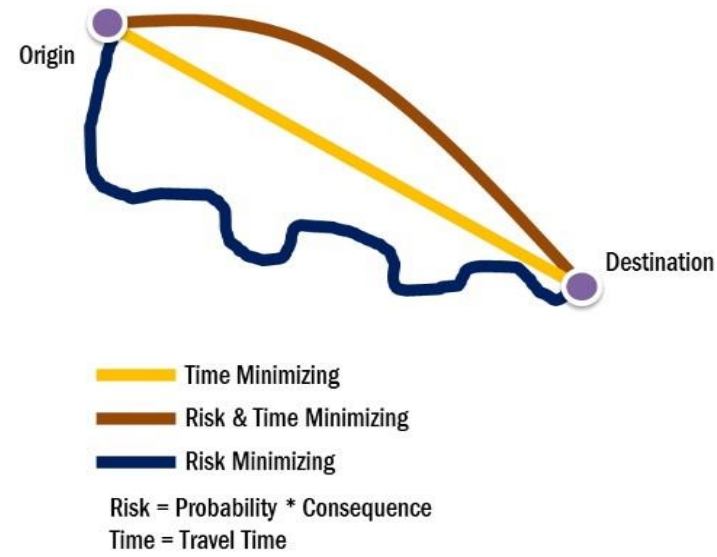

Figure 4. Comparing Paths

Path management system searches a safe path that is low accident possibility and less consequence as shown in Table 1. Therefore, the risk of road is determined as follow,

$$
\operatorname{Risk}(R)=\operatorname{Accident} \text { possibility }(P) \times \text { Consequence }(C)
$$

Table 1. Consequence

\begin{tabular}{c|l}
\hline classification & \multicolumn{1}{c}{ Victim } \\
\hline \multirow{3}{*}{ Population } & Population size \\
\cline { 2 - 2 } & $\begin{array}{l}\text { Daytime(employee population) / } \\
\text { Nighttime(residential population) }\end{array}$ \\
\hline \multirow{2}{*}{ Environment } & Environmental damage around the road \\
\cline { 2 - 2 } & Water supply protection area / River, forest \\
\hline
\end{tabular}

\begin{tabular}{|c|c|c|r|r|}
\hline Min & Max & Rank & \# of link \\
\hline 0.000000 & 0.000017 & 1 & 781,983 \\
\hline 0.000018 & 0.000047 & 2 & 206,423 \\
\hline 0.000048 & 0.000091 & 3 & 126,921 \\
\hline 0.000092 & 0.000155 & 4 & 100,622 \\
\hline 0.000156 & 0.000305 & 5 & 118,401 \\
\hline 0.000306 & 0.000564 & 6 & 96,741 \\
\hline 0.000565 & 0.000884 & 7 & 64,157 \\
\hline 0.000885 & 0.001586 & 8 & 67,203 \\
\hline 0.001587 & 99.999999 & 9 & 55,729 \\
\hline 100 & 10 & 861 \\
$y$
\end{tabular}

Figure 5. Road-link Risk in Korea

The risk is divided into 10 Ranks to facilitate system implementation. And then, the path management system searches a safe path based on the risk database as shown in Figure 5 . 


\subsection{Safe Driving through Journey Management System}

Fatality from drowsy driving is $34.5 \%$ in Korea. So Driver's fatigue management is very important. Generally, driver's fatigue management is carried out based on driving time. In Europe, drivers must take half an hour rest after 4 hours driving. On the other hand, drives should take 15minute rest after 2 hour driving in Korea. Furthermore, most of drivers don't obey regulation about rest time and there is no way to track down them. This system guides drivers to nearby rest area automatically after 2 hours of driving and give warning to drivers if they drive more than 2 hours to inducing rest time shown as shown in Figure 6.

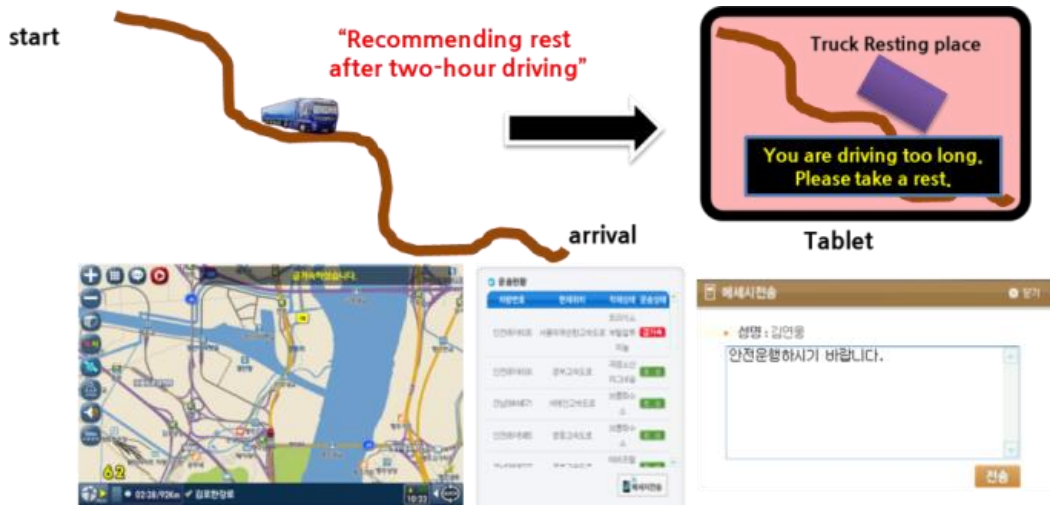

Figure 6. Journey Management

\subsection{Vehicle Health Management}

Vehicle health management is composed of basic information(vehicle model, tonnage, purchase day, year, identification number, tire replacement day, regular check-up day, equipment replacement day etc.,) and real-time status information(vibration, loading, fuel, tire pressure, cargo temperature etc.,) as shown in Figure 7. Basic information can prevent accident by comparing vehicle status before and after driving. Real-time status information detects accident symptom by monitoring status information of vehicle and freight in operation and notify accident symptom to driver and manager to prevent accident.

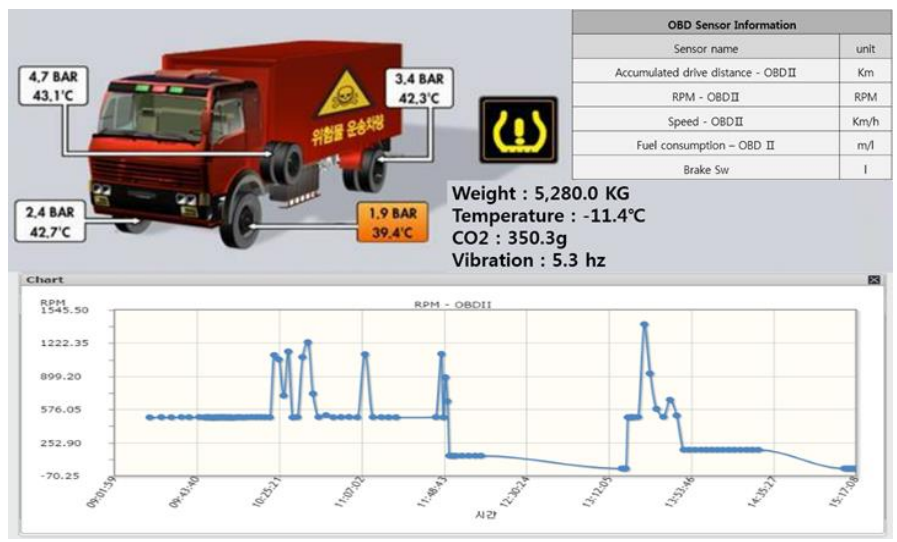

Figure 7. Vehicle Health Status

\subsection{Accident Response System}

Hazmat transportation accidents are reported by drivers or witnesses. But if driver is unconscious, accident report is fully depended on witnesses with not enough information about accident. Hazmat transportation accident needs quick correspondence to decrease 
secondary damage. Also sharing hazmat information can make it possible to correspond accurately.

The accident response system has two stages. The first stage is to detect the accident of the vehicle according to the degree of impact and the status of vehicle. And then in next stage, accident-related information like accident video, location, status information of vehicle and freight is transmitted to control center. Accident management system in control center generate accident data sheet automatically by combining transmitted information from accident vehicle and information of vehicles and drivers stored in server.

\section{Test and Result}

\subsection{Test Environment \& System}

In order to evaluate for integrated management system for hazmat transport, we test about 300 vehicles in real field. Selection of the test vehicle is based on the accident damage greater risk materials (chemicals, high-pressure gas and oil etc.). Test period is from August in 2014 to July in 2015.

Figure 8 shows the main view for the manager. It can manage vehicles based on GIS. There is a menu on the right side of the screen where you can view traffic information, incident status, roadside CCTV, local weather, the water protection zones and restricted areas. Also, vehicle information is viewed from the menu on the left side of the screen. On the other hands, a device(OS : Android 4.2, Touch LCD 10.1", dual camera(front and back), CPU is $1.6 \mathrm{GHz}$ ) installed on vehicle is shown in Figure 9.

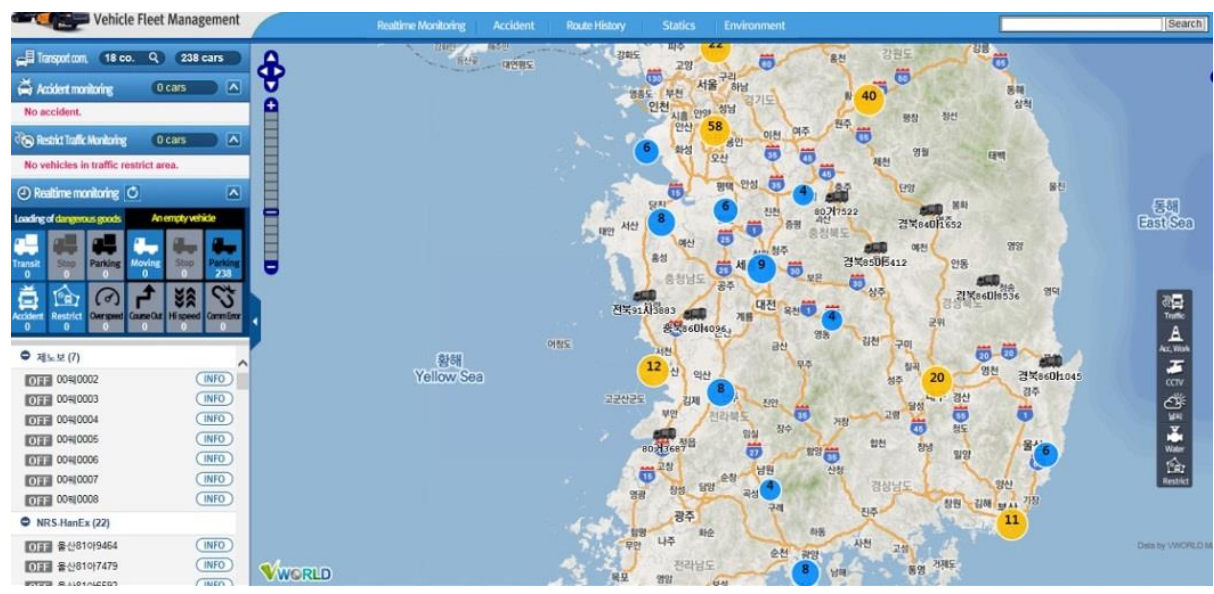

Figure 8. Over View of Main System

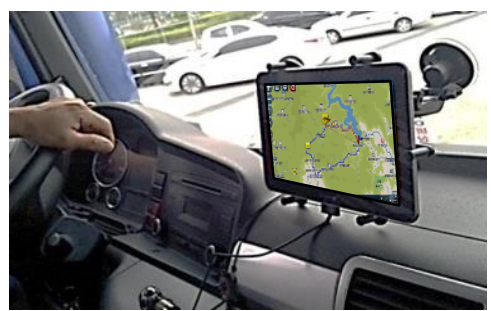

Figure 9. Device on a Vehicle

\subsection{Test Result}

Figure 10 is the alternative paths between Namyangju-si to Yangpung-gun. The green road is a drinking water source protection zone. 
Alternative path 1 has 28 minutes' time, $33.2 \mathrm{~km}$ distance and highest risk; alternative path 2 has 28 minutes' time, $53 \mathrm{~km}$ distance and lowest risk. Alternative path 3 has 47 minutes' time and $48 \mathrm{~km}$ distance and mid-risk. So, we considering the time, distance and risk. Alternative path 3 is the best path. And also, the path is perfect matching with the bypass road by government as shown in Figure 10.

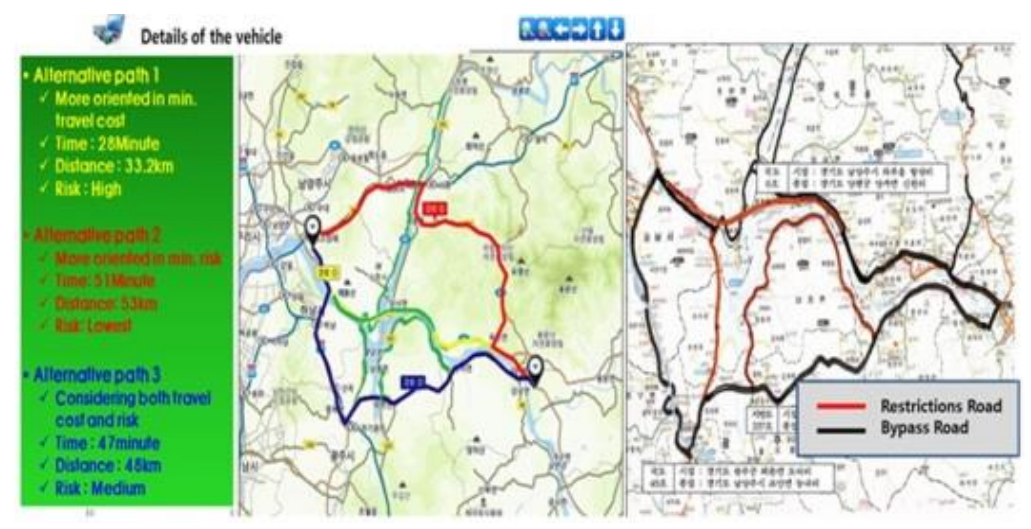

Figure 10. Navigator Searching path between Namyangju-si to Yangpunggun

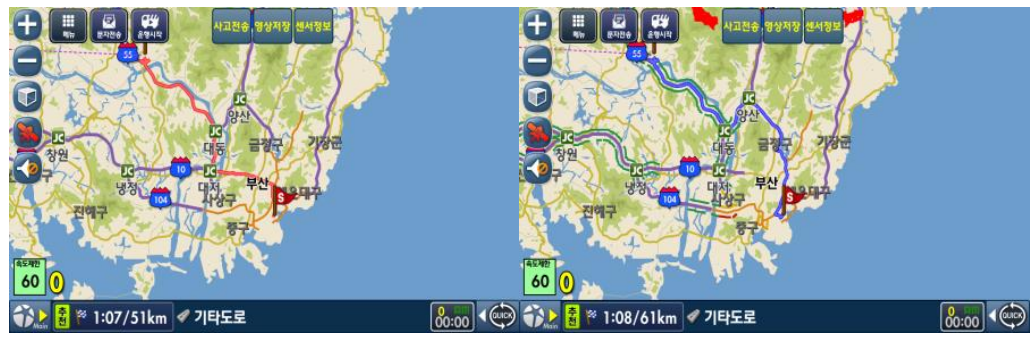

Figure 11. Navigator Searching path: normal searching path and (left), recommending path (right)

Figure 11 shows the result of route searching from Namcheon-dong, Busan to Samnyangjin, Gyeongsangnam-do. This test is conducted to evaluate whether searched route passes the central area of the city or not. Generally searched route passes the central area of the city and time is 67 minutes, distance is $51 \mathrm{~km}$, RISK is 1809 . On the other hand, route that avoids the central area of the city is takes about 68minute and distance is $61 \mathrm{~km}$, RISK is 593.

88 accident cases are accepted in test period. According to analysis result, most of cases, 87 accidents, are system malfunction and 1 case is false positive. We do not correspond to false positive after checking video from vehicle.

False positive is distinguished by analyzing video. In video, the vehicle stopped at weight stations and go up to weight measuring instrument. Vehicle is shocked when it enters into weight measuring instrument and stopped in the course of weight measuring. So it is recognized as accident.

System malfunction related to 87 accidents is happened continually in 34 vehicle terminals. To solve this problem, we repair the devices and test them again. Figure 12. shows the accident report created in case of an accident. The report has information about driver, vehicle, path and accident video. The manager who received the report is able to know pinpoint the accident situation(cause, location, time and current status of the accident). 


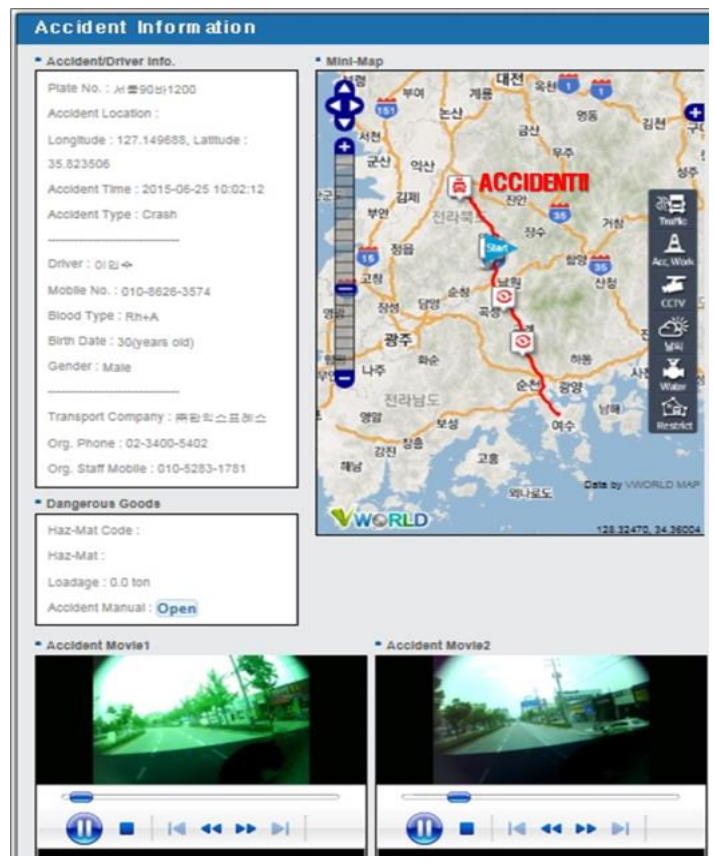

Figure 12. Accident Report

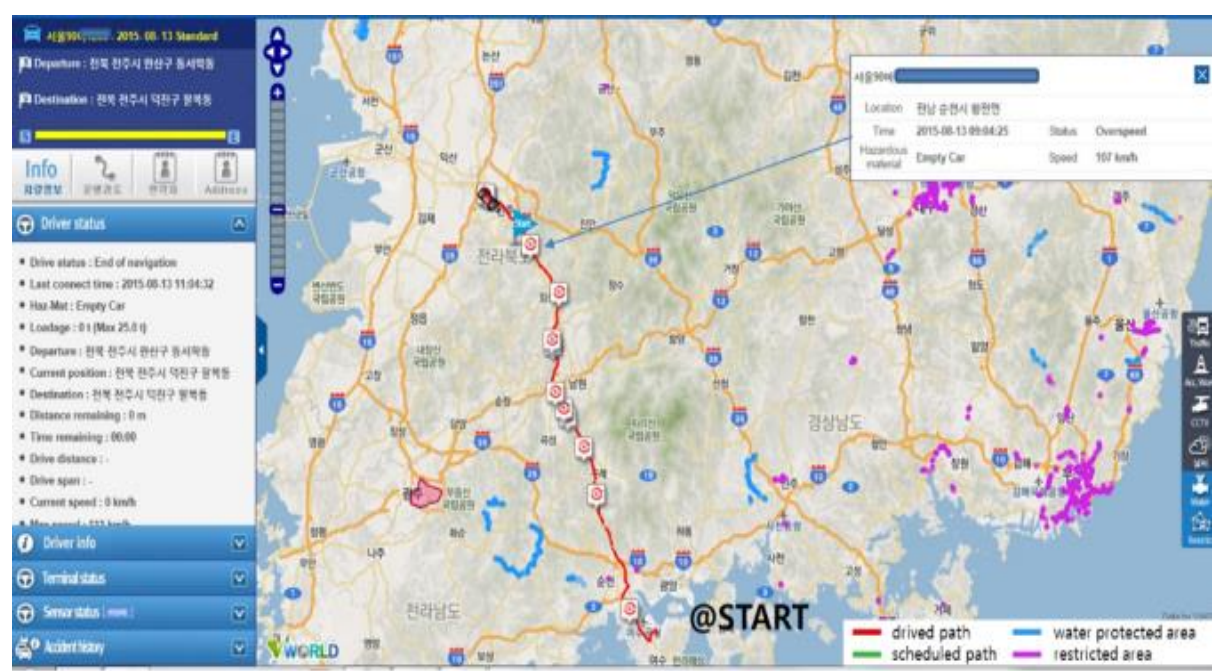

Figure 13. Overview of the Operation Result

Figure 13 shows the operation result. This route is a round trip to Yeosu from JeonJu. One of the speeding marks shows the speeding to $104 \mathrm{~km} / \mathrm{h}$. There are 9 times speeding in the route.

We analyzed the main route of one of the dangerous goods vehicles. The path was accumulated for 1 year. The result is shown in Figure. 14. The vehicle was characterized as being mainly used for a particular road. Therefore, in order to enable rapid accident response, the chemical response system will be equipped with such a road near. 


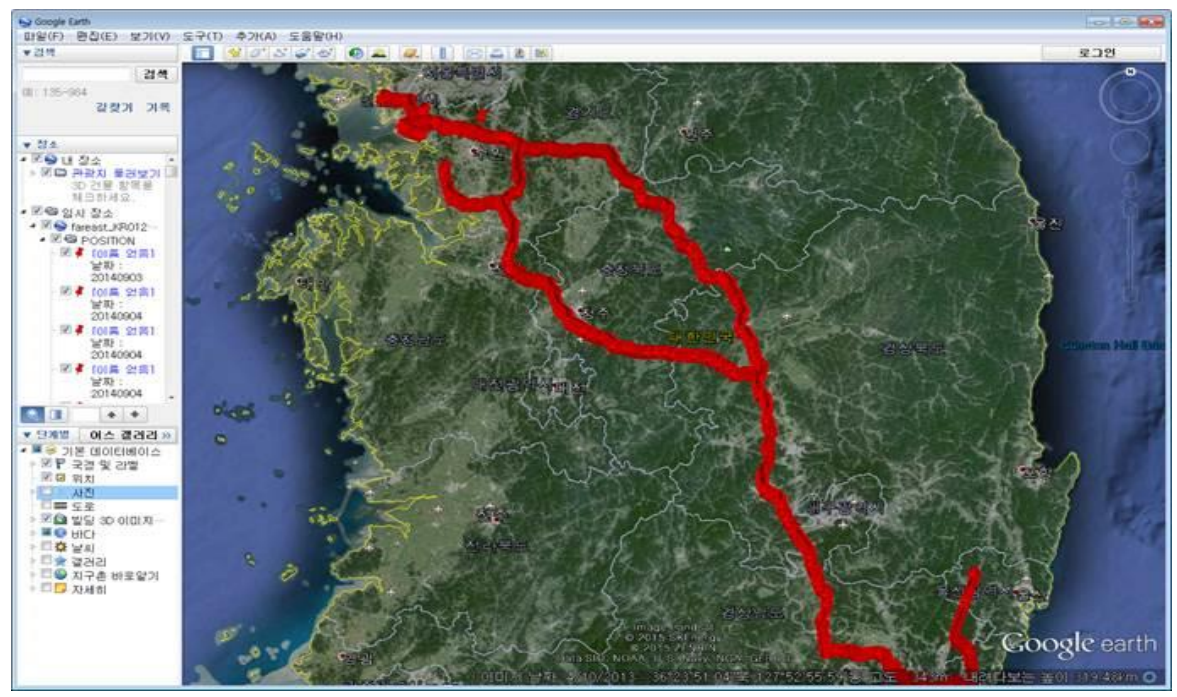

Figure 14. Accumulated Paths

\section{Conclusion}

This paper introduces introduced the integrated management system for dangerous goods transportation. The system has 4 features: path management, vehicle management, journey management and accident management. Especially, we described the path management based on risk of road and location based service to reduce secondary damage caused by dangerous goods vehicle accident. The vehicle accident has a serious damage to unspecified people and environment. Therefore, the path for safe transport of hazmat vehicles should consider the risk of road that includes the accident possibility and consequence. And all so, there are several restrictions road by legal for example a drinking water source protection zone. These roads should be excluded from the route search. The path management system gives risk, time and risk \& time minimizing paths. We recommend the risk \& time minimizing path because it has proper risk and time. So, the hazmat vehicle is able to run along the safe route except restricted road by legal. However, there is one problem how to combine the risk \& time. It was set empirically in this paper. So, how to combine the risk and time must be continued in future studies.

Also the accident management describes that it can automatically detect accident situation and then the accident information is quickly and accurately transferred to the relevant authorities.

If integrated management system is widely used, we expect to prevent accident in the process of the transport of dangerous goods, to respond to accident quickly and accurately. After all, the hazmat transportation accident damage will be reduced.

\section{Acknowledgements}

This research was supported by a grant from $R \& D$ Program of the Korea Railroad Research Institute, Republic of Korea.

\section{References}

[1] J. U. Won, J.W. Kim and Y.J.,” Adaptive Path Management considering Temporal and Circumstantial Variations," ASTL vol.107, pp.74-77(2015).

[2] J. U. Won, Suk Lee, Y,J Kwon and C.H. Choi. "Hazardous Materials Transportation Management System," proc. of Korea Society for railway conference, pp. 1468-1473( 2012)

[3] J.U. Won, Suk Lee, Y.J. Kwon and G.T. Kim, “ A study on managing a path for a safety transportation of dangerous goods," proc. of IEIE conference, pp. 1375-1378( 2013).

[4] Y. H. Lee and S.W. Kim, "Searching a Navigation Path to Avoid Danger Area for Safe Driving, “ Journal of IEIE, vol. 8, pp. 171-179(2013). 
[5] S. H. O, J.H. Ahn, S.H. and Gang and B.I. Moon, "A Combined Heuristic Algorithm for Preferencebased Shortest Path Search," Journal of IEIE, vol. 8. Pp. 74-84(2010)

[6] Y. Baek, Y.C. Choi, O.C. Kwon, and S.I. Choi, "Hazard Prevention Using Multi-Level Debris Flow Barriers," Journal of Korean Geo-Environmental society, Korean Geo-Environmental Society, vol. 8, pp. 15 23(2010).

[7] Jeon, G.U., Lim, Y.H., Nam, S.Y., Jang S.J., Jeong, Y.S., Yong, S.Y, "Sediment and woody debris trap effect of h-type slit dam with model experiment", 2010 Summer conference of Korean Forest Society, Korean Forest Society, pp. 349-350(2010).

[8] Kim, J.H., Jeon, G.U., Seo, J.I., Yoon, J.U., Kwon, S.M., Kim, Y.R, "Effects of Float-Board Screen for Catching Drift Woods and Debris Flows in Urban Areas", 2013 Summer conference of Korean Forest Society, Korean Forest Society, pp. 913-914(2013).

[9] Kim, J.H., Lee, Y.S., Park, K.B, “A Study on Model Experiment for Evaluation of Debris Flow's Impact Force Characteristics", Journal of Korean Geo-Environmental Society, Korean Geo-Environmental Society, Vol. 26, No.11, pp.5-15(2010).

[10] Ministry of Construction and Transportation, "Flood Prevention for Mountain Road Design Manual", (2007).

[11] Ministry of Land, Transport and Maritime Affairs, "Road Drain Related Design and Management Guidelines", (2012).

[12] Oh, C.Y. and Jun, K.W, "A Study on Transport the Hydrological Property of Debris Accumulation at Flood", 2008 conference of Korea Water Resources Association, Korea Water Resources Association, pp.1747-1752(2008).

[13] Baek, Y., Choi, Y.C., Kwon, O.C., Choi, S.I, "Hazard Prevention Using Multi-Level Debris Flow Barriers, Journal of Korean Geo-Environmental society", Korean Geo-Environmental Society, no. 11, vol. 8, pp.15-23(2010).

[14] Berzi, D., and Larcan, E, "Laboratory investigation of dam-break flow of a mixture of water and granular mater", Debris-flow hazards mitigation: Mechanics, Prediction, and Assessment, Millpress, pp.223-228(2007).

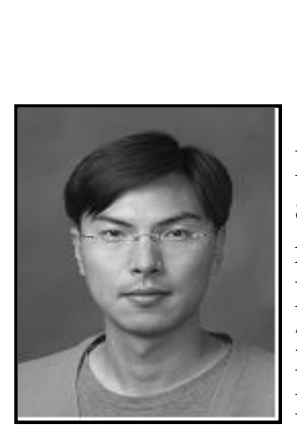

\section{Authors}

Jong-Un Won, he received the B.S. and M.S. degrees from the Dept. of Control and Measurement Engineering, Korea Maritime and Ocean University, Busan, Korea, in 1996 and 1998, respectively and Ph.D. degree from the Dept. of Electronic Engineering, Kyungpook National University, Daegu, Korea, in 2004. Currently, he is a Researcher of the Logistics system Research Team, Green Transport \& Logistics Institute, Korea Railroad Research Institute(KRRI). Uiwang-si, Gyeonggi-do, Korea. His research interests include image processing, sensor network, IoT, RFID.

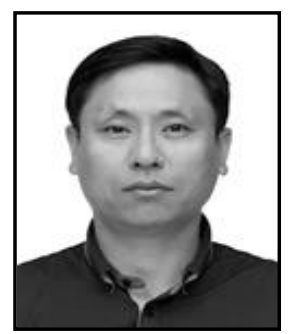

Jae-Won Kim, he received the B.S. degree from the Dept. of Computer Science, Dongguk University, Seoul, Korea, in 1992, and M.S. and Ph.D. degrees from the Dept. of Computer Science, Korea University, Seoul, Korea in 1997 and 2011, respectively. Currently, he is a Researcher of the Natural Science Research Institute, Korea University, Seoul, Korea. His research areas include ubiquitous computing, NGIS, RFID, Sensor Network.

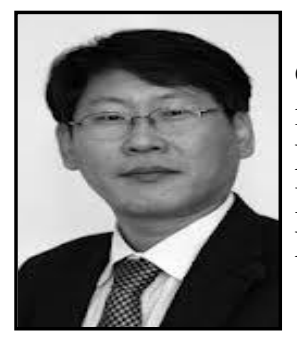

Yong-Jang Kwon, he received the B.S., M.S. and Ph.D. degrees from the Dept. of Business, Hanyang University, Korea, in 1995, 1997 and 2006. Currently, he is a team leader of the Logistics system research team, Korea Railroad Research Institute(KRRI). His research areas include logistics system, Economics. 